\title{
EFL Learners' Surface Taxonomic Errors of Using Appropriate Verbs in Writing Descriptive Text
}

\author{
Azizah Husda ${ }^{1}$, Fachri Yunanda ${ }^{2}$, Anis Anggraini Siregar ${ }^{3}$ \\ ${ }^{1,2,3}$ Department of English Teaching, Universitas Prima Indonesia \\ email: azizahhusda@unprimdn.ac.id
}

\begin{tabular}{c}
\hline ArtiCLE INFO \\
\hline Received \\
$20 / 07 / 2020$ \\
Revised \\
$23 / 07 / 2020$ \\
Accepted \\
$27 / 07 / 2020$ \\
\end{tabular}

Keywords (9

Bold):

English for Foreign

Language,

Taxonomic Error,

Writing Desciptive Text.

\begin{abstract}
This article dealt with surface taxonomic errors of using appropriate verbs in writing descriptive text. The objectives are to investigate the types of common errors done by EFL learners by describing the dominant errors and also to elaborate on the reason why the learners did the errors in the descriptive text. The subjects of this research consist of 30 Senior High learners from some schools as the representative samples. Descriptive Qualitative Method with a case study design applies to the research. In collecting the data, essay tests and interviews were used. Findings show that there were some types of surface taxonomic errors such as misformation with 110 (60,11\%) errors, omissions with 45 (24,59\%) errors, addition with $16(8,74 \%)$ errors, and misordering with 12 (6,55\%) errors. Thus, misformation is the dominant type found. All of the errors committed to 183 of using appropriate verbs in writing descriptive text. Beyond the dominant errors such as misformation and omission, the errors occurred because some learners put the wrong tenses and verbs. Furthermore, the learners had less comprehension in structures related to the organization of the descriptive text.
\end{abstract}

How to cite: Husda, A., Yunanda, F., Siregar, A. A. (2020). EFL Learners' Surface Taxonomic Errors of Using Appropriate Verbs in Writing Descriptive Text. English Teaching and Linguistics Journal, 1(2), 71 78.

\section{INTRODUCTION}

Indonesian learners seem to have problems in mastering English grammar because English and Indonesian language are slightly different. This phenomenon is one of the factors that can trigger learners to make errors. Any errors produced can be caused by learners' lack of English language, less vocabulary, minimum knowledge of genre texts, and their grammar test is under the rate of standard minimum score, and also because of their mother tongue which always influences them in practising English as Foreign Language. The teacher should be aware of those errors and do something to avoid them by doing some correction. Brown (2000) states that error is noticeable deviation from adult grammar or native speaker reflecting the inter language competence of learner, while mistake refers to performance factor such as: memory, limiation, spelling fatigue, and emotional strain. The identification of errors is a result from lack of knowledge of the rules of the language.

Speaking of error, it is often connected to mistake. Some people even think that the term of error and mistake are the same and they ommonly cannot see the distinction between both of them. In fact, errors and mistakes are different in the linguistic point of view. The learners who make a mistake are able to recognize the mistakes and able to correct themselves if it is. On the 
other hand, error is systematic. That is, it is likely to occur repeatedly and is not recognized by the learners as errors.

Error can be used as a tool of evaluation for measuring, the mastery of language being learnt. (Ellis, 2008) states that error is a lack of knowledge and mistake is the learners' posse's knowledge of the correct form and it is just slipping up. In addition, errors can also help the teacher even the curriculum designer to improve the material given or designed. (Foster, 2005) states that an error is an individual language user's deviation from standard language norms in grammar, syntax, pronounciation and punctuation. Language learning and language error cannot be separated each other. Language error frequently happen in the language learning process. All language learners tend to make errors when they learn a language especially for foreign language learners. Foreign language learners may have some confusion to recognize the language because of the influence of their mother tongue. Besides, (Setiyadi, Sukirlan, \& Mahpul, 2016) state that language learners whose mother tongue have no tenses tend to have more difficulties in learning a target language which has some complicated tenses such as English and their L1 (bahasa Indonesia) does not imposes such rules of tenses.

As a matter of fact, error are often being made by learners during their learning process, and it becomes an inevitable part of learning, kind of study has been made to observe and analyze those error further, namely error analysis. A number different descriptions for error analysis have been identified. (Rahmawati, 2011) argues that error analysis is a type a linguistic analysis that focuses on the process of identifying, and describing the learner's error in target language learning. While, (Abi, 2003) adds that error analysis can be viewed as a type analysis that focuses on errors committed by learners. Thus, error analysis is studied in order to find out something about the learning process and about the strategies employed by human beings learning another language. By studying samples of language produced by the foreign language learners, the researchers can discover, or at least make the information of what should learners think about the rules of the foreign language are.

Committing errors is one of the most unavoidable things in the world. Learners, in te process of learning language, profit from the errors that they make by obtaining feddback to make new attempts that successively approximate their desired objectives. Vahdatinejad (2008) maintains that error analyses can be used to determine what a learner still needs to be taught. It provides the necessary information about what is lacking in the learner's competence. By analyzing the errors, the learners get much more correction to master English well because it has some benefits for both learners and teachers such as showing them in what aspect of grammar is difficult for them, describing the errors made, knowing the occurrence of the errors of how the learners can learn from their mistakes so that they will not do repetitions and exploring what strategies appropriated for instructional process.

According to (Brown, 2000), there are some reasons of why errors commonly occurred in target language namely; interlingual transfer, intralingual transfer, context of learning, and communication strategy used between learners and teachers. Meanwhile, there are four common types of errors; lingusitic category, surface strategy, comparative analysis, and communicative effect (Dulay, et.al, 2017). Error in the linguistic category is based on linguistic items. The linguistic category taxonomies classify errors according to either or both the language components and the particular linguistic constituent the error affects. The language components include phonology (pronunciation), syntax and morphology (grammar), semantics and lexicon (meaning and vocabulary), and discourse (style). The surface strategy taxonomy as a classification of language errors based on how the surface structures are altered. Surface strategy taxonomy emphasize on the way surface structures are changed. It analyzed the errors in which learners may omit necessary items or add, misform, or even misorder components of the sentence. The comparative taxonomy classifies errors based on comparison between the structure of language learner errors and certain other types of construction. These comparisons

EFL Learners' Surface Taxonomic Errors of Using Appropriate Verbs in Writing Descriptive Text (Husda, A) 
have yielded the two major error categories in this taxonomy, namely development errors and interlingual errors. Two other categories that have been used in comperative analysis taxonomies are derived from the first two ambiguous errors, which are classified as either development or interlingual.

Development errors are errors similat to those made by children learning the target language as the first language. Whereas, interlingual errors as mentioned earlier interlingual errors are similar in structure to semantically equivalent phrase or sentence in the learner's native language. The fourth type is the communicative effect classification which deals with errors from the perspective of their effect on the listener or reader. It focuses on distinguishing between errors that seem to cause miscommunication. There are two types of errors in this communicative effect taxonomy. They are global errors and local errors. (Dulay, et.al, 2017) argue that global errors that effect overall sentence organization significantly hinder communication because of the wide syntactic scope of such error. The most systematic global errors include the wrong order, missing, wrong, or misplaced the sentence connectors. Missing clues to signal obligatory expections to persuasive syntactic rules. Local errors that effect single elements in a sentence do not hinder communication significantly. These errors in noun and verb inflection, articles, auxiliaries and the formation of quantifiers.

In this research, the scope is specified to surface taxonomy strategy of how the surface structures are altered. Surface strategy taxonomy emphasize on the way surface structures are changed in which is classified to omission, addition, missformation, and misordering. As well as errors may occur in a language, language has the integrated skills. The skills are categorized into productive and receptive. Listening and reading are classified to receptive while speaking and writing are productive. Writing is an activity of how people put the idea, thougt and knowledge on a piece of paper. The writing skill is complex and sometimes diffcult to teach, requiring mastery not only of grammatical and rhetorical devices but also of conceptual and judgmental elements. (Brown, 2000) explains that writing is thinking process, because writing is a process of putting ideas down on paper to transform thought or ideas into words and give them structure and coherent organization. In writing, learners are able to express idea, opinion, experience, comment or information in the form of written language. In making a good writing in English, learners have to know all rules in writting, not only in general rule but also in a specific rule. The specific rule here is about sentence. To make a good sentence, learners have to pay attention that a sentence they make is contructed by a complete aspect like subject, verb, and complement. A construction is not named as a sentence if it has no verb or to be.

Writing is a medium of human communication that represents language and emotion with signs and symbols. In most languages, wrting is a complement to speech or spoken language. Writing is not a language to be read. Within a language system, writing relies on many of the same structures as speech, such as vocabulary, grammar, and semantics, with the added dependency of a system of signs or symbol. From the brief explanation of writing, writing is closely related to a text. There should be a text produced from the ideas elaborated from human cognitive skill. Text is the original words of something written, printed, or spoken, in contrast to a summary or paraphrase. (Siahaan, 2008) defines that text is a meaningful lingusitic unit in a context. A linguistic unit contains phoneme or a morpheme or a phrase or clause, or a sentence or discourse. A text genre is type of written or spoken discourse, texts are classified into genres on the basis of the intent of the communicator. According to (Pardiyono, 2007), genre is a text type that serves in frame of refrence, so the text can be made effetively, effective from precion of purpose, selection and preparation of text element, and precision of using grammar. Also, he adds that there are some genres of text such as narrative, descriptive, anecdote, report, procedure, analytical exposition, hortatory exposition, explanation, recount, and spoof text. In this research, it is objected to descriptive text because the text is commonly put and discussed in the textbook as it is a type of written text which has the specific function to give description about animate or inanimate (Pardiyono, 2007). Every text has own structure, according to (Artono, 2008) the 
generic structures of a description are identification and description which the stage of identification that identifies the phenomenon to be described. While the description contains important features such as physical pearance, qualities, and other characteristic from thing that the writer describes.

From the explanation above, there are some objectives clearly stated that first, it is to investigate the types of surface taxonomic errors made by EFL learners of using appropriate verbs in descriptive text. Second, it aims to find the causes or reasons why learners do some types of surface taxonomic errors beyond the dominant type. Also, this research gives some contributions to identify, classify, describe, and analyze learner's error in target language learning. Then, it is to find the feedback, used as reference in language learning in order to prevent or minimize the errors committed by the foreign learners.

\section{METHODS}

The research approach applies descriptive qualitative with a case study design. The This study is intended to describe EFL learners who make some surface taxonomic errors of using appropriate verbs in the descriptive text. Researchers took 30 learners as the samples among some representative private schools. Those samples were randomly observed through the essay test and the interview. Those instruments are used to collect the data about the errors in writing the descriptive text. First, the researchers observed that the teacher had explained the lesson and the instruction about the descriptive text and the generic structure of the text. Learners were allowed to take some topics given to write the descriptive text through their ideas. To do the essay test, 45 minutes was allocated. Then, after submission, the teacher marked the score by looking for some errors. On another day, researchers asked the teacher to take some learners to be interview. The interview test was about finding out the causes of errors made by the learners. Finally, the researchers took the data to get analyzed based on the model of (Miles, et.al, 2014), namely data reduction, data display and conclusion drawing/verification.

In data reduction, the researchers took the data required from essay test and interview is from type of surface taxonomic errors, how they occur, why the learners make the errors. In this case, the data which was not supported and not required had been discarded. Then, in the data display presented all of the types of surface taxonomic errors found with the precentages in order to explore the dominant type. The presentation was applied on the table. Data display was purposed to elaborate the objectives of the research. At the final step, the conclusions were drawn to verify the findings and the discussion of the research. (see Figure 1).

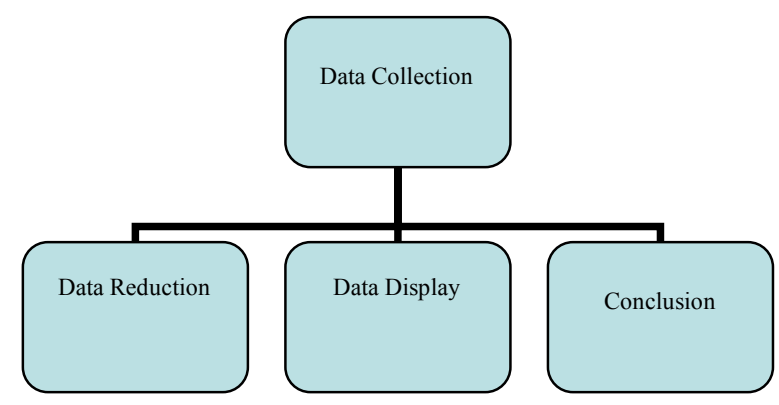

Figure 1. Technique of Analyzing Data

\section{RESULT AND DISCUSSION}

The data were not about the scores got by the learners but how they made the errors of using appropriate verbs in the descriptive text. The dominant type of surface taxonomic errors brought the ideas to investigate the objectives of the research. From the essay tests given to the learners, there were 183 errors which were classified into misordering, misformation, ommision,

EFL Learners' Surface Taxonomic Errors of Using Appropriate Verbs in Writing Descriptive Text (Husda, A) 
and addition. While the interview tests support the errors with the evidences. The results from the essay tests shown that the four types of the surface taxonomic errors were drawn in Table 1. Table 1.

The Average of Four Types of the Surface Taxonomic Errors

\begin{tabular}{cccc}
\hline No & TYPES OF ERRORS & QUANTITY & PERSENTAGE \\
\hline 1. & Misordering & 12 & $6,55 \%$ \\
2. & Misformation & 110 & $60,11 \%$ \\
3. & Addition & 16 & $8,75 \%$ \\
4. & Omission & 45 & $24,59 \%$ \\
& Total & $\mathbf{1 8 3}$ & $\mathbf{1 0 0}$
\end{tabular}

So, it can be concluded that the the dominant type of errors was misformation with the number of 110 errors $(42,10 \%)$ of using the appropriate verbs in the descriptive text. In the first type, errors of misordering were characterized by incorrect placement of a morpheme or group of morpheme in an utterance. There was only 1 learner who made error of misordering with the number of 12 errors $(6,55 \%)$. This type was also the lowest one among the others errors. here are some data taken from the learner

(i)

$\begin{array}{ll}\text { Error } & : \text { She teaching is very good for me } \\ \text { Correction } & : \text { She } \text { is teaching very good for me } \\ \text { Error } & \text { : What is a sunny day! } \\ \text { Correction } & \text { : What a sunny day } i s !\end{array}$

From the example above, it is clearly shown that the learner did not pay attention to grammar or having grammarless to sentence pattern. The second sentence was also misplaced, in this case, the learner ignored the exclamation form of using the verb of $i s$. The learner can be identified that he had some confusion to put the verb in the right place. Thus, this error was done because of the intralingual transfer of the target language as the negative transfer of items within the target language, or put another way, the incorrect generalization of within the target language is a major factor in foreign language learning.

The second part discussed was misformation error with the highest percentage $60,11 \%$ because of 110 errors made. There were 13 learners made this type of error because of using the wrong morpheme or sructure. As the example, look at this sentence.

(ii) Errors : I was in one grade school.

Correction : I am first grade senior high school

In this case, the learner was identified as the one who put the wrong tense in the descriptive text because it should be the present tense used. The learner did not consider the generic structure of the text, thus it means the instructions of the lesson was ignored. The learner here, need much more understanding of writing which was related to the skills of listening to teacher and reading the instruction during the language learning process because this error was affected by the communicative strategy. See the comparison of the further example below.

(iii) Error : My hobby is swimming and playing basketball.

Correction : My hobbies are swimming and playing basketball.

Comparing to the previous example, the learner did not put the correct form of the auxiliary to mark the pluralization. Eventhough the learner put es to the word hobby, still the learner should make the appropriate verb are to relate the tense and the pluralization. In this context, the student to th It means that the learner did misused of using to be. It should be are but it was is in the sentence, and it is incorrect. It was clearly found that the intralingual transfer was the source of this error made. 
Third, errors of omission were found 45 within $24,59 \%$ in the worksheets. Those errors were made by 9 learners because they omitted a necessary element of word. Here are some data from the learners' worksheets:

$$
\begin{array}{ll}
\text { Error } & : \text { playing fotball happy with my friend. } \\
\text { Correction } & : \text { I'm playing football happy with my friend. }
\end{array}
$$

This error was identified because of the context of learning. The learner was seemed to use the spoken form in stating the ideas thus, the word I' $m$ was deleted. It means that the context of learning was associated with the social context of language acquisition to produce other types of errors. The sociolinguistic context of natural can give certain language acquisition which may itself be a source of error. Consider another example with the same error such as follows.

$$
\begin{array}{ll}
\text { Error } & \text { : I playing mobile legends with my friend. } \\
\text { Correction } & \text { : I am playing mobile legends with my friend. }
\end{array}
$$

The auxiliary am being hidden to discover the error. Yet, there was a comparison between the previous example because this error was not affected by the context of learning instead of using the intralingual transfer within the target language supported with the grammarless or the rules of the language.

Last but not least, the last type of surface taxonomic error made by learners was addition. Errors of addition were the opposite of ommision. There were 16 errors $(8,75 \%)$ of the error of addition was made by 7 learners. These errors happened because the learners add a necessary element of word. here are some data from the learners' sentences:

$$
\begin{array}{ll}
\text { Error } & : \text { I like to have some family. (like to) } \\
\text { Correction } & : \text { I have some family. }
\end{array}
$$

From the representative example above, the learner added the wrong verb which was not appropriate to the sentence because the addition verb was identified meaningless. In this part, the error was affected by both the context of learning and also the communicative strategy. In the xontext of learning, the learner did not consider that using double verb within a sentence was stated to misused and led to out of rule of the language. While in the communicative strategy, this error made misperception of using the spoken language in the written text.

\section{SUGGESTION AND CONCLUSION}

Based on the findings and discussion, it can be concluded that there were $60,11 \%$ errors of misformation, $6,55 \%$ errors of misordering, $8,75 \%$ errors of ommision, and $24,59 \%$ errors of addition. After analyzing the data, the dominant type of surface taxonomic error made by the learners based on the highest percentages was the error of misformation of using appropriate verbs in writing the descriptive text where there were 13 learners made the error of misformation. One focus was detected from a learner himself making misordering among other learners. It means that the language acquisition in the context learning needs attention.

Moreover, those results were found from the interview tests to the learners after doing the essay tests and corrected by the teacher. Some of the learners discovered themselves that they had less comprehension of using the rules of tenses or sentence patterns, awareless of paying attention to the generic structures of the descriptive text, and careless of using the form of appropriate verbs and also other parts of speech such as the use of adjective, noun, preposition, adverb, and conjunction. Thus, it means that it is necessary to consider some effective strategy done by the teachers in writing skills of any genre of the text.

By conducting this research, it can be suggested that the learners should often make composition in enhancing the writing skills as the productive skill in language because writing is the complex skill which is associated and influenced by the other skills such as listening, speaking, and reading. Those three skills could be the clues to improve the writing skill. Besides, teachers at present, should give more practice and clear explanation about writing any text by applying some appropriate teaching strategy as the keys of monitoring and evaluating the

EFL Learners' Surface Taxonomic Errors of Using Appropriate Verbs in Writing Descriptive Text (Husda, A) 
learners. For further research, this research can be the reference in enhancing the learners' competence especially for preventing some errors in writing skill.

\section{REFERENCES}

Abi, S. N. (2003). An Analysis of Errors in Arabic Speakers' English Writings. http://abisamra03.tripod.com/nada/languageacq-erroranalysis.html.Artono, et. al. 2008. English in Focus: for Grade VII Junior High School (SMP/MTs). Jakarta: Pusat Perbukuan, DEPIKNAS.

Brown, D. H. 2000. Principles of Language Learning \& Teaching. (4th ed.). New York: Longman.

Dulay, H. et.al. 1982. Language Two. Oxford: Oxford University Press.

Ellis, R. 2008. The Study of Second Language Acquisition (2nd ed.). Oxford: Oxford University Press.

Foster, J. (2005). Good Reason for Noting Bad Grammar: Empirical Investigations into the Parsing of Unggrammatical Written English. PhD thesis, Trinity College, University of Dublin, Dublin, Ireland.

Miles, et. al. 2014. Qualitative data Analysis. Jakarta: UI Press.

Pardiyono. 2007. Pasti bisa. Yogyakarta: Andi.

Rahmawati, R. (2011). Error Analysis on the Use of Simple Present Tense in Paper Assignment of Writing Subject Made by the Fourth Semester Students of English Department at STAIN Salatiga in the Academi Year of 2011/2012. Unpublished Thesis. STAIN English Department: Salatiga.

Setiyadi, A. B., Sukirlan, M., \& Mahpul, . (2016). How Successful Learners Employ Learning Strategies in an EFL Setting in the Indonesian Context. English Language Teaching, 9(8), 28. https://doi.org/10.5539/elt.v9n8p28

Siahaan, et. al. 2008. Generic Text Structure. Yogyakarta: Graha Ilmu.

Vahdatinejad, S. (2008). Learners' Error Analysis and Attitude towards Teacher Feedback Using a Selected Software: a Case Study. Unpublished Masters Thesis. Universiti Kebangsaan Malaysia, Bangi. 